Acta Cryst. (1999). B55, 937-946

\title{
Structure and thermal behavior of the new superprotonic conductor $\mathrm{Cs}_{2}\left(\mathrm{HSO}_{4}\right)\left(\mathrm{H}_{2} \mathrm{PO}_{4}\right)$
}

\author{
Calum R. I. Chisholm* and Sossina M. Haile \\ Materials Science 138-78, California Institute of Technology, Pasadena, CA 91125, USA. \\ E-mail: smhaile@its.caltech.edu
}

(Received 3 May 1999; accepted 20 July 1999)

\begin{abstract}
Ongoing studies of the $\mathrm{CsHSO}_{4}-\mathrm{CsH}_{2} \mathrm{PO}_{4}$ system, aimed at developing novel proton conducting solids, resulted in the new compound $\mathrm{Cs}_{2}\left(\mathrm{HSO}_{4}\right)\left(\mathrm{H}_{2} \mathrm{PO}_{4}\right)$ (dicesium hydrogensulfate dihydrogenphosphate). Single-crystal X-ray diffraction (performed at room temperature) revealed $\mathrm{Cs}_{2}\left(\mathrm{HSO}_{4}\right)\left(\mathrm{H}_{2} \mathrm{PO}_{4}\right)$ to crystallize in space group $P 2_{1} / n$ with lattice parameters $a=$ 7.856 (8), $b=7.732$ (7), $c=7.827$ (7) $\mathrm{A}$, and $\beta=$ $99.92(4)^{\circ}$. The compound has a unit-cell volume of $468.3(8) \AA^{3}$ and two formula units per cell, giving a calculated density of $3.261 \mathrm{Mg} \mathrm{m}^{-3}$. Six non-H atoms and two $\mathrm{H}$ atoms were located in the asymmetric unit, with $\mathrm{SO}_{4}$ and $\mathrm{PO}_{4}$ groups randomly arranged on the single tetrahedral anion site. Refinement using all observed reflections yielded weighted residuals of 0.0890 and 0.0399 based on $F^{2}$ and $F$ values, respectively. Anisotropic temperature factors were employed for all six non-H atoms and fixed isotropic temperature factors for the two $\mathrm{H}$ atoms. The structure contains zigzag chains of hydrogen-bonded anion tetrahedra that extend in the [010] direction. Each tetrahedron is additionally linked to a tetrahedron in a neighboring chain to give a planar structure with hydrogen-bonded sheets lying parallel to (101). Thermal analysis of the superprotonic transition in $\mathrm{Cs}_{2}\left(\mathrm{HSO}_{4}\right)\left(\mathrm{H}_{2} \mathrm{PO}_{4}\right)$ showed that the transformation to the high-temperature phase occurs by a two-step process. The first is a sharp transition at $334 \mathrm{~K}$ and the second a gradual transition from 342 to $378 \mathrm{~K}$. The heat of transformation for the entire process $(\sim 330-382 \mathrm{~K})$ is $44 \pm 2 \mathrm{~J} \mathrm{~g}^{-1}$. Thermal decomposition of $\mathrm{Cs}_{2}\left(\mathrm{HSO}_{4}\right)\left(\mathrm{H}_{2} \mathrm{PO}_{4}\right)$ takes place at much higher temperatures, with an onset of approximately $460 \mathrm{~K}$.
\end{abstract}

\section{Introduction}

Many solid acid sulfates and selenates undergo structural phase transitions that lead to high proton conductivity at slightly elevated temperatures (Baranov et al., 1984; Merinov et al., 1991; Pawlowski et al., 1990; Pawlaczyk et al., 1986). Our recent investigations of the $\mathrm{CsHSO}_{4}-\mathrm{CsH}_{2} \mathrm{PO}_{4}$ system have shown that mixed sulfate-phosphate compounds, such as $\beta$ $\mathrm{Cs}_{3}\left(\mathrm{HSO}_{4}\right)_{2}\left(\mathrm{H}_{2-x}\left(\mathrm{~S}_{x} \mathrm{P}_{1-x}\right) \mathrm{O}_{4}\right)$ (Haile et al., 1997) and
$\alpha-\mathrm{Cs}_{3}\left(\mathrm{HSO}_{4}\right)_{2}\left(\mathrm{H}_{2} \mathrm{PO}_{4}\right)$ (Haile, Lentz et al., 1995), can also undergo such transitions. These studies of complex solid acids have been undertaken with the aim of clarifying the role of hydrogen bonding, $\mathrm{XO}_{4}$ group chemistry and other chemical features in superprotonic behavior. In the present work we describe the synthesis, thermal behavior and room temperature structure of $\mathrm{Cs}_{2}\left(\mathrm{HSO}_{4}\right)\left(\mathrm{H}_{2} \mathrm{PO}_{4}\right)$, the newest member of the caesium sulfate-phosphate solid acid family. Discerning the structure-property relationship in this new compound is expected to yield particularly valuable insight into phase transition and proton transport mechanisms, as $\mathrm{Cs}_{2}\left(\mathrm{HSO}_{4}\right)\left(\mathrm{H}_{2} \mathrm{PO}_{4}\right)$ undergoes a superprotonic transition at a significantly lower temperature (Chisholm \& Haile, 1999) than the other compounds in this system and, furthermore, as described below, it has a unique hydrogen-bond network.

\section{Crystal growth and characterization}

Single crystals of $\mathrm{Cs}_{2}\left(\mathrm{HSO}_{4}\right)\left(\mathrm{H}_{2} \mathrm{PO}_{4}\right)$ were obtained from aqueous solutions of cesium carbonate, sulfuric acid and phosphoric acid, in which the mole ratio of Cs: $\mathrm{SO}_{4}: \mathrm{PO}_{4}$ was fixed at 10:5:5. Just enough deionized water was added to a mixture of the carbonate and acids to cause dissolution, and the solution was then gently heated until completely transparent. After 7-8 d at $285 \mathrm{~K}$, a solution so prepared yielded a crystalline mixture of $\mathrm{Cs}_{2}\left(\mathrm{HSO}_{4}\right)\left(\mathrm{H}_{2} \mathrm{PO}_{4}\right)$ and $\alpha$ $\mathrm{Cs}_{3}\left(\mathrm{HSO}_{4}\right)_{2}\left(\mathrm{H}_{2} \mathrm{PO}_{4}\right)$ (Haile, Kreuer \& Maier 1995) in a volume ratio of approximately 70:30. The $\mathrm{Cs}_{2}\left(\mathrm{HSO}_{4}\right)\left(\mathrm{H}_{2} \mathrm{PO}_{4}\right)$ was present in the form of small, plate-like crystals, approximately $0.1 \times 1 \times 3 \mathrm{~mm}^{3}$ in size. The conditions under which it crystallized suggest $\mathrm{Cs}_{2}\left(\mathrm{HSO}_{4}\right)\left(\mathrm{H}_{2} \mathrm{PO}_{4}\right)$ is the 'unidentifiable' compound earlier referred to by Calkins (1996).

The composition of the new compound was established using a Jeol JXA-733 electron microprobe. For this purpose a single crystal was mounted in an epoxy resin, polished and then evaporatively coated with carbon. Microprobe data were collected at four positions on the sample for statistical averaging and to determine the chemical homogeneity of the material. Measured X-ray peak intensities were converted to elemental weight percentages using the CITZAF 
program (Armstrong, 1995). The compounds $\mathrm{Cs}_{2} \mathrm{SO}_{4}$, $\mathrm{RbH}_{2} \mathrm{PO}_{4}$ and $\mathrm{Cr}_{2} \mathrm{O}_{3}$ served as standards. These analyses yielded normalized atomic per cents of 19.0 (9), 8.0 (4), 9.5 (12) and 63.7 (14) for Cs, S, P and O, respectively, which compare favorably to the ideal values of 16.6, 8.3, 8.3 and 66.6. Furthermore, the mole ratios of Cs:(S + P) and of P:S were 1.10 (16) and 1.2 (2), respectively, both within one standard deviation of the ideal values of $1: 1$. The experimental error in any particular measurement was greater than the variation between results obtained at different positions on the sample, indicating that the material was chemically homogeneous to within our measurement limits. The average elemental weight \% total was 85.0 (10), significantly below the expected value of $100 \%$. Subsequent $\mathrm{X}$-ray structural analysis, however, indicated there were no other species in the compound (e.g. waters of crystallization) and this low elemental weight \% total was taken to be an artifact of the visible beam damage that occurred during data collection.

\section{Thermal analysis}

The high-temperature behavior of $\mathrm{Cs}_{2}\left(\mathrm{HSO}_{4}\right)\left(\mathrm{H}_{2} \mathrm{PO}_{4}\right)$ was examined using a Perkin-Elmer DSC 7 digital scanning calorimeter. Samples were heated, in a flowing nitrogen atmosphere, from 293 to $473 \mathrm{~K}$ at heating rates which varied from 5 to $20 \mathrm{~K} \mathrm{~min}^{-1}$. The onset of thermal decomposition was probed by thermal gravimetric analysis. Data were collected with a Perkin-Elmer TGA 7 at heating rates of 10 and $40 \mathrm{~K} \mathrm{~min}^{-1}$, again, under flowing nitrogen, over the temperature range 295-1273 K.

A typical DSC curve obtained from $\mathrm{Cs}_{2}\left(\mathrm{HSO}_{4}\right)\left(\mathrm{H}_{2} \mathrm{PO}_{4}\right)$ on both heating and cooling is shown in Fig. 1. In Fig. 2 the weight of $\mathrm{Cs}_{2}\left(\mathrm{HSO}_{4}\right)\left(\mathrm{H}_{2} \mathrm{PO}_{4}\right)$ as a function of temperature is presented. These particular data were collected at a

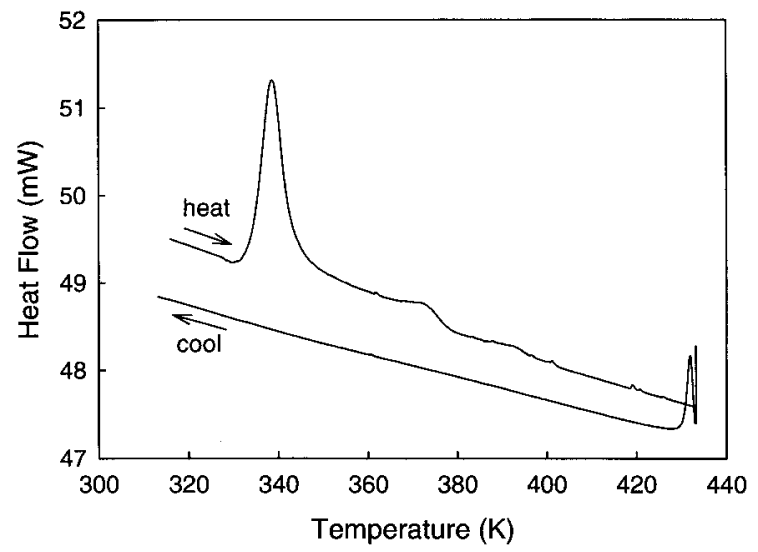

Fig. 1. DSC curve obtained for $\mathrm{Cs}_{2}\left(\mathrm{HSO}_{4}\right)\left(\mathrm{H}_{2} \mathrm{PO}_{4}\right)$ at a heating rate of $5 \mathrm{~K} \mathrm{~min}^{-1}$. Data collected on both heating and cooling, as indicated by arrows on the figure. heating (and cooling) rate of $5 \mathrm{~K} \mathrm{~min}^{-1}$ and are representative of all the data in that the measured curves were rather insensitive to heating rate. The results reveal that $\mathrm{Cs}_{2}\left(\mathrm{HSO}_{4}\right)\left(\mathrm{H}_{2} \mathrm{PO}_{4}\right)$ undergoes structural changes over the temperature range $334-378 \mathrm{~K}$ which are unrelated to decomposition; its weight is stable to $\sim 460 \mathrm{~K}$, Fig. 2. Moreover, as reported elsewhere, the conductivity of $\mathrm{Cs}_{2}\left(\mathrm{HSO}_{4}\right)\left(\mathrm{H}_{2} \mathrm{PO}_{4}\right)$ increases by nearly three orders of magnitude as it is heated over the temperature range of this transition to a value of $1.5 \times$ $10^{-3} \Omega^{-1} \mathrm{~cm}^{-1}$ at $368 \mathrm{~K}$ (Chisholm \& Haile, 1999). The high-temperature phase of $\mathrm{Cs}_{2}\left(\mathrm{HSO}_{4}\right)\left(\mathrm{H}_{2} \mathrm{PO}_{4}\right)$ is thus 'superprotonic' in nature and, furthermore, stable over a rather wide temperature range. The transition of $\mathrm{Cs}_{2}\left(\mathrm{HSO}_{4}\right)\left(\mathrm{H}_{2} \mathrm{PO}_{4}\right)$ to its superprotonic state is unusual in that it takes place by a two-step process: the first is a sharp transformation that has its thermal peak centered at $338 \mathrm{~K}$ and the second a gradual transformation that takes place from approximately 342 to 378 K, Fig. 1 . The heat of transformation for the entire process $(334-378 \mathrm{~K})$ is $44 \pm 2 \mathrm{~J} \mathrm{~g}^{-1}$. The reverse transformation was not detected upon cooling and initial observations indicate that $\mathrm{Cs}_{2}\left(\mathrm{HSO}_{4}\right)\left(\mathrm{H}_{2} \mathrm{PO}_{4}\right)$ can remain in its high temperature form at room temperature for several hours.

The decomposition of $\mathrm{Cs}_{2}\left(\mathrm{HSO}_{4}\right)\left(\mathrm{H}_{2} \mathrm{PO}_{4}\right)$ occurs in several stages, Fig. 2 . The first weight loss region occurs over the temperature range $460-570 \mathrm{~K}$. Approximately $5 \%$ of the mass is lost, which corresponds to 1.3 molecules of water per formula unit or almost complete dehydration. This dehydration step is followed by a plateau from 570 to $740 \mathrm{~K}$, a second and more gradual weight loss region from 740 to $950 \mathrm{~K}$, over which a loss of approximately $7.5 \mathrm{wt} \%$ takes place, a third plateau from 950 to $1100 \mathrm{~K}$, and finally a third weight loss region which begins at $1100 \mathrm{~K}$ and is not complete at $1273 \mathrm{~K}$, the highest temperature examined. At present, the nature of the volatile species that evolve at high temperature is unknown, but probably includes $\mathrm{SO}_{x}$ gases.

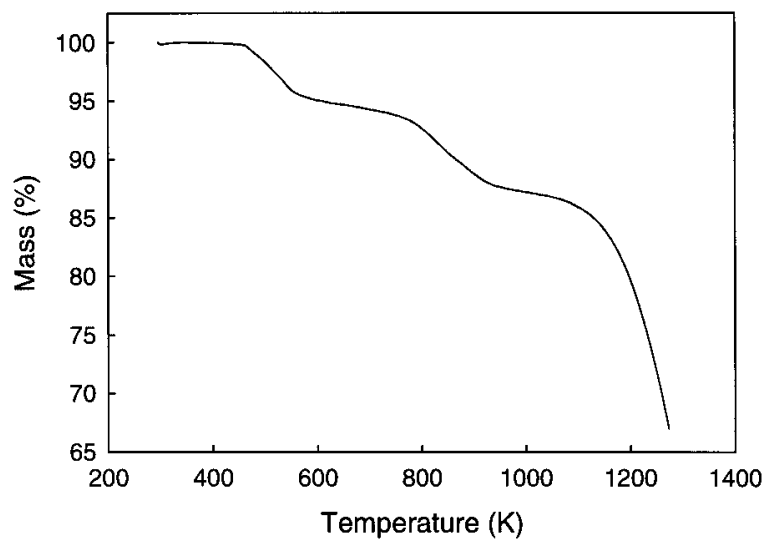

Fig. 2. Weight as a function of temperature (TGA curve) measured for $\mathrm{Cs}_{2}\left(\mathrm{HSO}_{4}\right)\left(\mathrm{H}_{2} \mathrm{PO}_{4}\right)$ at a heating rate of $5 \mathrm{~K} \mathrm{~min}^{-1}$. 


\section{Structure determination}

\subsection{Procedure}

Single-crystal X-ray diffraction intensity data were obtained on a Syntex four-circle diffractometer using Mo $K \alpha$ radiation $(\lambda=0.71073 \AA)$. Data were collected at room temperature from an as-synthesized specimen measuring $0.05 \times 0.15 \times 0.2 \mathrm{~mm}^{3}$ in size. The lattice parameters of the crystal were established from the positions of 20 diffraction peaks and revealed $\mathrm{Cs}_{2}\left(\mathrm{HSO}_{4}\right)\left(\mathrm{H}_{2} \mathrm{PO}_{4}\right)$ to be monoclinic with lattice parameters $a=7.856$ (8), $b=7.732$ (7), $c=7.827$ (7) $\AA$, and $\beta=99.92(4)^{\circ}$. An analysis of the systematic absences showed the space group to be $P 2_{1} / n$. Table 1 provides the remaining data collection parameters, as well as some crystallographic data and parameters related to the refinement. $\dagger$

The structure was solved by first finding the Cs atoms via direct methods and then the $X$ (where $X=\mathrm{S}, \mathrm{P}$ ) and $\mathrm{O}$ atoms from successive Fourier difference maps. In this manner, one Cs atom and one $\mathrm{XO}_{4}$ group were found in the asymmetric unit. Since $\mathrm{S}^{6+}$ and $\mathrm{P}^{5+}$ are isoelectronic and thus have almost identical $\mathrm{X}$-ray scattering lengths, the exact nature of the central cation in the $\mathrm{XO}_{4}$ group could not be determined directly from structure refinements. On the basis of the chemical analysis, however, the occupancy at the $X$ atom site was tentatively taken to be $0.5 \mathrm{P}$ and $0.5 \mathrm{~S}$.

An examination of the intertetrahedral $\mathrm{O}-\mathrm{O}$ bond lengths suggested the presence of two hydrogen bonds, the first linking $\mathrm{O}(1)$ and $\mathrm{O}(1)^{\prime}$, and the second linking $\mathrm{O}(3)$ and $\mathrm{O}(4)$. If one assigns one proton to each of these bonds, $\mathrm{H}(1)$ and $\mathrm{H}(2)$, respectively, the chemical formula of the new mixed sulfate-phosphate then contains 1.5 protons per Cs atom, or three protons per formula unit. Such a proton content, in turn, implies, for charge balance reasons, that there should be one $\mathrm{S}$ atom and one $\mathrm{P}$ atom per formula unit, giving an overall stoichiometry of $\mathrm{Cs}_{2}\left(\mathrm{HSO}_{4}\right)\left(\mathrm{H}_{2} \mathrm{PO}_{4}\right)$. This result is in agreement with the chemical analysis and from hereon the $X$ atom was taken to definitively be comprised of 0.5 $\mathrm{P}$ and $0.5 \mathrm{~S}$.

Initial proton coordinates were established from the location of peaks in Fourier difference maps in the vicinity of $\mathrm{O}(1)-\mathrm{O}(1)^{\prime}$ and $\mathrm{O}(3)-\mathrm{O}(4)$. In the case of $\mathrm{H}(1)$, a peak was found at a distance of $\sim 1 \AA$ from $\mathrm{O}(1)$ and also somewhat removed from the inversion center relating $\mathrm{O}(1)$ and $\mathrm{O}(1)^{\prime}$. The angle formed between the $X$ atom, the $\mathrm{O}(1)$ atom and this site, $106.3^{\circ}$, was close to the ideal tetrahedral value of $109.5^{\circ}$. The proton was thus taken to reside at this position (in a doubleminimum symmetric potential well) and to have a fixed occupancy of 0.5 . Introduction of the $\mathrm{H}(1)$ proton in this

$\dagger$ Supplementary data for this paper are available from the IUCr electronic archives (Reference: BS0007). Services for accessing these data are described at the back of the journal.

Table 1. Experimental details

Crystal data

Chemical formula

Chemical formula weight

Cell setting

Space group

$a(\AA)$

$b(\AA)$

$c(\AA)$

$\beta\left({ }^{\circ}\right)$

$V\left(\AA^{3}\right)$

$Z$

$D_{x}\left(\mathrm{Mg} \mathrm{m}^{-3}\right)$

Radiation type

Wavelength (@)

No. of reflections for cell parameters

$\theta$ range $\left({ }^{\circ}\right)$

$\mu\left(\mathrm{mm}^{-1}\right)$

$F(000)$

Temperature (K)

Crystal size (mm)

Crystal color

Crystal mounted

Data collection

Diffractometer

Data collection method

Absorption correction

$$
T_{\min }
$$

$T_{\max }$

No. of measured reflections

No. of independent reflections

No. of observed reflections

Criterion for observed reflections

$R_{\text {int }}$

$\theta_{\text {max }}\left({ }^{\circ}\right)$

Range of $h, k, l$

No. of standard reflections

Intensity decay (\%)

Decay correction

Refinement

Refinement

$R\left[F^{2}>2 \sigma\left(F^{2}\right)\right]$

$w R\left(F^{2}\right)$

$S$

No. of reflections used in refinement

No. of parameters used

$\mathrm{H}$-atom treatment

Weighting scheme

$(\Delta / \sigma)_{\max },(\Delta / \sigma)_{\text {mean }}$

$\Delta \rho_{\max }\left(\mathrm{e} \AA^{-3}\right)$

$\Delta \rho_{\min }\left(\mathrm{e} \AA^{-3}\right)$

Anisotropic thermal parameters

Extinction coefficient

Source of atomic scattering factors

Computer programs

Structure solution

Structure refinement

Structure depiction

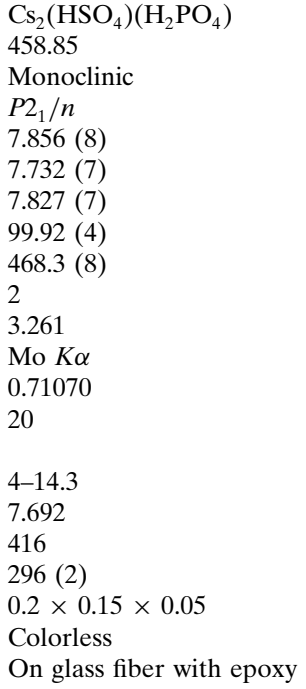

Syntex four-circle

$\theta-2 \theta$ scans

Empirical, $\psi$ scan

0.36

1.00

2629

1364

1210

$I \geq 2 \sigma(I)$

0.0470

29.99

$-11 \rightarrow h \rightarrow 10$

$-10 \rightarrow k \rightarrow 10$

$0 \rightarrow l \rightarrow 11$

3

0.7

Applied

Full-matrix least-squares on $F^{2}$ 0.0348

0.0855

1.042

1361

49

Constrained refinement (see text)

$w=\left[\sigma^{2}\left(F_{o}^{2}\right)+(0.0502 P)^{2}\right.$

$+0.23049 P]^{-1}$, where $P$

$=1 / 3\left[\max \left(F_{o}^{2}, 0\right)+2 F_{c}^{2}\right]$

$0.516,0.031$

1.431

$-1.324$

All non-H atoms

0.0116 (12)

Cromer \& Waber (1974)

SHELXS86 (Sheldrick, 1985)

SHELXL93 (Sheldrick, 1993)

ATOMS (Dowty, 1999) 
manner reduced the weighted residual, $w R\left(F^{2}\right)$, from 0.0900 to 0.0895 . In comparison, introduction of a proton precisely at the inversion center yielded a residual of 0.0897 .

In the vicinity of $\mathrm{O}(3)$ and $\mathrm{O}(4)$ two Fourier difference peaks of comparable heights were found, one closer to $\mathrm{O}(3), \mathrm{H}(2 a)$, and the other closer to $\mathrm{O}(4)$, $\mathrm{H}(2 b)$. The absence of a symmetry element relating the two $\mathrm{O}$ atoms indicates that $\mathrm{H}(2)$ resides in an asymmetric potential well. Typically, such a bond contains a single minimum and one can identify the donor $\mathrm{O}$ atom on the basis of an elongation of the $X-\mathrm{O}$ bond (Ichikawa, 1987). That is, $X-\mathrm{O}_{D}$ distances are typically longer than $X-\mathrm{O}$ or $X-\mathrm{O}_{A}$ distances, so as to minimize possible overbonding of donor $\mathrm{O}$ atoms in the $X-\mathrm{O}_{D}-$ $\mathrm{H} \cdots \mathrm{O}_{A}-X$ bond. Identification of the donor atom, in turn, would allow one to determine which of the possible $\mathrm{H}(2)$ sites is occupied. In the present case, the $X-\mathrm{O}(3)$ and $X-\mathrm{O}(4)$ bond lengths are comparable (see Table 4 ), and neither $\mathrm{H}(2)$ site can be eliminated as an improbable proton position solely on the basis of such crystal chemical arguments. The Fourier difference peak closer to $\mathrm{O}(4)$ had a slightly greater electron density and a more reasonable $\mathrm{O}-\mathrm{H}$ distance than the peak nearer to $\mathrm{O}(3)$, thus favoring it as the probable proton position: $d_{\mathrm{O}(4)-\mathrm{H}(2 b)}$ was $0.95 \AA$, as compared to a $\mathrm{O}(3)-\mathrm{H}(2 a)$ distance of $0.81 \AA$. However, the angle formed by the $X$ atom, the $\mathrm{O}$ atoms and potential proton sites $[\angle X-$ $\mathrm{O}(3)-\mathrm{H}(2 a) \simeq 115^{\circ}$ and $\left.\angle X-\mathrm{O}(4)-\mathrm{H}(2 b) \simeq 122^{\circ}\right]$ suggested the site closer to $\mathrm{O}(3)$ should reflect the true position of $\mathrm{H}(2)$. There was, therefore, sufficient ambiguity to warrant that both sites be examined rather closely. Refinements performed in which the $\mathrm{H}(2 a)$ site was fully occupied [in addition to the half occupied $\mathrm{H}(1)$ site] resulted in a final residual of 0.0895 , whereas those performed in which the $\mathrm{H}(2 b)$ site was fully occupied yielded a value of 0.0890 . An alternate refinement incorporating both sites, $\mathrm{H}(2 a)$ and $\mathrm{H}(2 b)$, each with half occupancy, yielded an only slightly improved residual of 0.0889 , despite the greater number of model parameters. Consequently, the $\mathrm{H}(2 a)$ site was eliminated from the refinement and full occupancy assigned to $\mathrm{H}(2 b)$, hereafter referred to simply as $\mathrm{H}(2)$.

In the final stages of the refinement, anisotropic displacement parameters were employed for all non-H atoms and fixed isotropic parameters of $U_{\text {iso }}=0.08 \AA^{2}$ (a value approximately twice that of the $\mathrm{O}$ atoms) for the two $\mathrm{H}$ atoms. In addition, an overall extinction parameter was refined. Proton positions were restrained by 'affixing' $\mathrm{H}(1)$ to $\mathrm{O}(1)$ and, similarly, $\mathrm{H}(2)$ to $\mathrm{O}(4)$, such that the $X-\mathrm{O}-\mathrm{H}$ angles were each constrained to a value of $109.5^{\circ}$, but the $\mathrm{O}-\mathrm{H}$ distances and $\mathrm{O}_{3} X-\mathrm{O}-$ $\mathrm{H}$ torsion angles were refined. The final residuals, based on 1361 independent reflections, were $w R\left(F^{2}\right)=0.0890$ and $R(F)=0.0399$. The data were weighted as described in Table 1 and refinements were performed against $F^{2}$ values. All calculations were performed using the
Table 2. Atomic coordinates and equivalent isotropic displacement parameters $\left(\AA^{2}\right)$ for $\mathrm{Cs}_{2}\left(\mathrm{HSO}_{4}\right)\left(\mathrm{H}_{2} \mathrm{PO}_{4}\right)$

\begin{tabular}{lllrl}
\multicolumn{5}{c}{$U_{\text {eq }}=(1 / 3) \Sigma_{i} \Sigma_{j} U^{i j} a^{i} a^{j} \mathbf{a}_{i} \cdot \mathbf{a}_{j}}$. \\
& $x$ & $y$ & \multicolumn{1}{c}{$z$} & \multicolumn{1}{l}{$U_{\text {eq }}$} \\
$\mathrm{Cs}(1)$ & $0.7280(1)$ & $0.1588(1)$ & $0.1180(1)$ & $0.031(1)$ \\
$\mathrm{S} / \mathrm{P} \dagger$ & $0.7565(1)$ & $0.1621(1)$ & $-0.3887(1)$ & $0.022(1)$ \\
$\mathrm{O}(1)$ & $0.6584(4)$ & $0.0269(3)$ & $0.4937(4)$ & $0.032(1)$ \\
$\mathrm{O}(2)$ & $0.8377(2)$ & $0.2882(2)$ & $-0.4882(3)$ & $0.034(1)$ \\
$\mathrm{O}(3) \neq$ & $0.6287(2)$ & $0.2447(2)$ & $-0.2880(2)$ & $0.033(1)$ \\
$\mathrm{O}(4) \S$ & $0.8930(2)$ & $0.0690(3)$ & $-0.2607(2)$ & $0.039(1)$
\end{tabular}

$\dagger$ Fixed site occupancy of $0.5 \mathrm{~S}$ and $0.5 \mathrm{P}$. $\ddagger$ Fixed site occupancy of 0.5 . $\S$ Probable neighboring interstitial site at $0.6482,0.3470$ and -0.2775 .

SHELXS and SHELXL programs (Sheldrick, 1985, 1993).

At this stage, all features of the structural model appeared reasonable, however, the stoichiometry of $\mathrm{Cs}_{2}\left(\mathrm{HSO}_{4}\right)\left(\mathrm{H}_{2} \mathrm{PO}_{4}\right)$, in which $\mathrm{S}$ and $\mathrm{P}$ are present in a simple 1:1 ratio, suggested some type of ordering of the sulfur and phosphorus species. Since only one crystallographic site exists for $\mathrm{P} / \mathrm{S}$ in $\mathrm{Cs}_{2}\left(\mathrm{HSO}_{4}\right)\left(\mathrm{H}_{2} \mathrm{PO}_{4}\right)$, ordering can only be accommodated via a reduction in the space group or the formation of a superstructure. Refinements in alternative space groups were only briefly pursued as the systematic absences strongly indicated $P 2_{1} / n$ and the structural model in $P 2_{1} / n$ fits the data very well (as evidenced by the low residuals). However, the possibility that a superstructure existed and might have been overlooked in the initial stages of the unit-cell determination was closely examined by both photographic and diffractometer methods. Longexposure axial photographs ( $1.5 \mathrm{~h}$ at $40 \mathrm{kV}$ and $30 \mathrm{~mA}$ ) were taken for all three axes. In total, only three, very weak, possible superstructure diffraction spots, along (h00), were observed. Diffractometer data were collected a second time, assuming a doubling of the $a$ axis. Superstructure peaks in the intensity data were, for the most part, unobserved. Of 2726 peaks collected with an odd value of $h$, only 26 (or $1 \%$ ) had an intensity of greater than $3 \sigma$ and only 7 an intensity greater than $4 \sigma$. Despite the few number of possible superstructure peaks, attempts to refine the structure in this larger unit cell were pursued. As might be expected, these efforts were unsuccessful as a result of the high correlations between pseudosymmetry related parameters, even in highly constrained refinements. The absence of superstructure peaks may be attributed either to the similarity of the X-ray scattering lengths of $\mathrm{S}^{6+}$ and $\mathrm{P}^{5+}$ or to the true absence of a superstructure. In the case of other mixed sulfate phosphates examined in this system, ordering of $\mathrm{S}$ and $\mathrm{P}$ atoms was accompanied by other structural changes (see Haile, Kreuer \& Maier, 1995, for example), which allowed us to unambiguously determine the proper space group and unit cell, even when only X-ray data were available. Thus, we are led to 
conclude that ordering of sulfur and phosphorous species is unlikely in $\mathrm{Cs}_{2}\left(\mathrm{HSO}_{4}\right)\left(\mathrm{H}_{2} \mathrm{PO}_{4}\right)$.

\section{Results}

Atomic coordinates and thermal parameters for $\mathrm{Cs}_{2}\left(\mathrm{HSO}_{4}\right)\left(\mathrm{H}_{2} \mathrm{PO}_{4}\right)$ are given in Tables 2 and 3, respectively. The compound is isostructural to $\left(\mathrm{NH}_{4}\right)_{2}\left(\mathrm{HSO}_{4}\right)\left(\mathrm{H}_{2} \mathrm{PO}_{4}\right)$ (Averbuch-Pouchot \& Durif, 1981) and $\mathrm{K}_{2}\left(\mathrm{HSO}_{4}\right)\left(\mathrm{H}_{2} \mathrm{PO}_{4}\right)$ (Averbuch-Pouchot \& Durif, 1980), compounds for which S/P disorder has also been proposed. A thermal ellipsoid representation of the structure projected along [100] is shown in Fig. 3. As might be expected for such a compound, the cation ellipsoids are almost spherical, whereas the oxygen ellipsoids reveal thermal displacements that are, for the most part, greatest perpendicular to the $X-\mathrm{O}$ bond. In the case of $\mathrm{O}(3)$ the thermal displacements are, in fact, greatest along the direction of the angular bisector of the $X-\mathrm{O}(3)-\mathrm{O}(4)$ angle and this may be linked to the presence of a possible proton interstitial site at $\mathrm{H}(2 a)$. Nevertheless, the thermal ellipsoid about $\mathrm{O}(3)$ is in no way unreasonable.
Interatomic distances for the cation polyhedra are listed in Table 4, as are the interatomic angles for the $\mathrm{XO}_{4}$ tetrahedra. The sum of the bond valences at each of the cation sites is also provided in Table 4 . The valences of the $\mathrm{Cs}-\mathrm{O}, \mathrm{S}-\mathrm{O}$ and $\mathrm{P}-\mathrm{O}$ bonds were calculated according to

$$
\begin{gathered}
S(\mathrm{Cs}-\mathrm{O})=\exp \left[\left(2.417-d_{\mathrm{Cs}-\mathrm{O}}\right) / 0.37\right] \\
S(\mathrm{~S}-\mathrm{O})=\exp \left[\left(1.624-d_{\mathrm{S}-\mathrm{O}}\right) / 0.37\right]
\end{gathered}
$$

and

$$
S(\mathrm{P}-\mathrm{O})=\exp \left[\left(1.617-d_{\mathrm{P}-\mathrm{O}}\right) / 0.37\right],
$$

where $d_{\mathrm{Cs}-\mathrm{O}}, d_{\mathrm{S}-\mathrm{O}}$ and $d_{\mathrm{P}-\mathrm{O}}$ are the caesium-tooxygen, sulfur-to-oxygen and phosphorous-to-oxygen distances, respectively, measured in $\AA$ (Brown \& Altermatt, 1985). The chemical similarity of $P$ and $S$, and thus the similarity of their bond-valence contributions to the $X-\mathrm{O}$ bond, imply that one need not know a priori the $\mathrm{P}$ and $\mathrm{S}$ occupancies on a mixed occupancy site in order to estimate a meaningful bond valence. Accordingly, the bond-valence sum in Table 4 has been calculated assuming occupancy at the $X$ atom site by $0.5 \mathrm{P}$ and $0.5 \mathrm{~S}$.

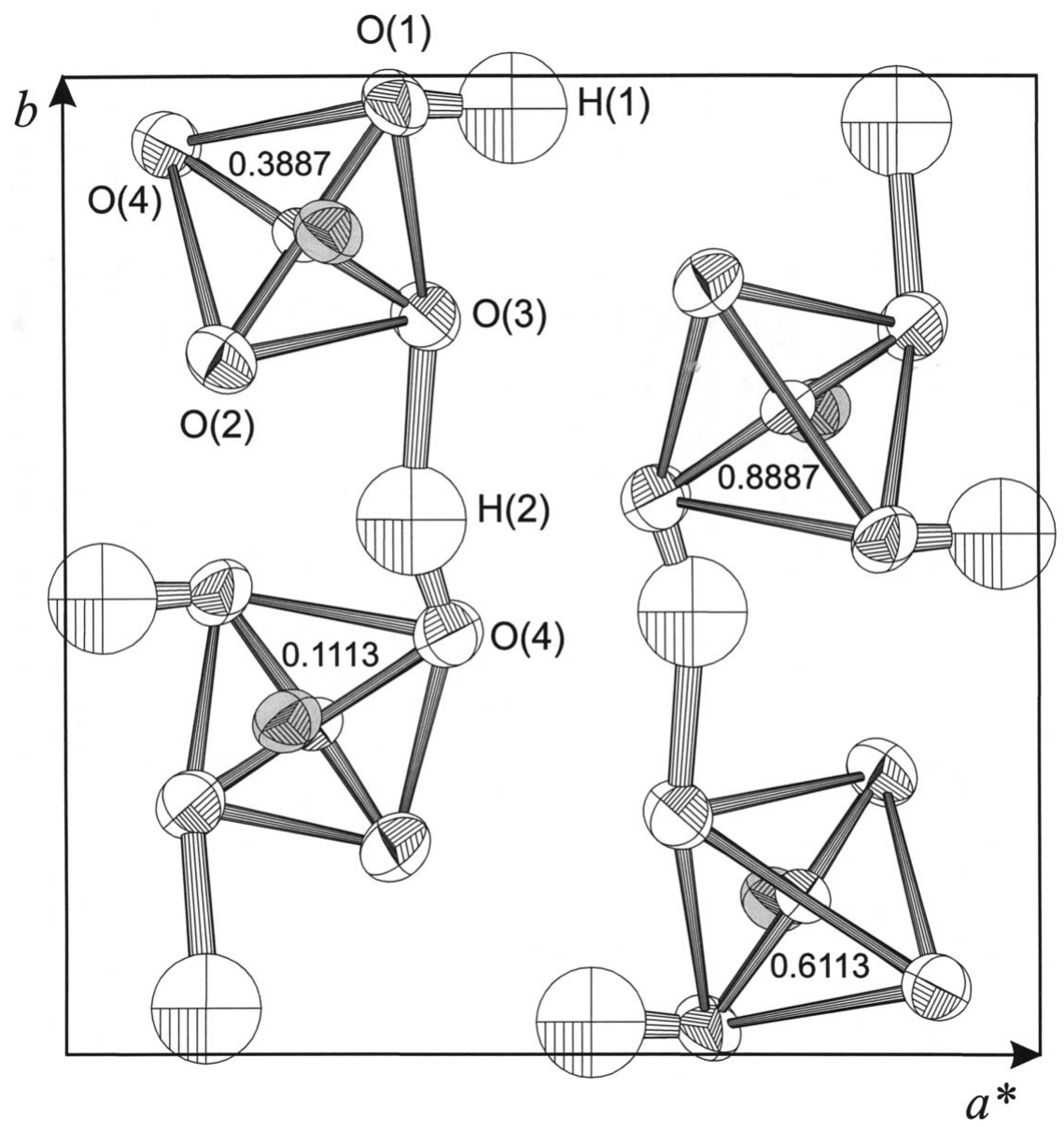

Fig. 3. Thermal ellipsoid representation of the structure of $\mathrm{Cs}_{2}\left(\mathrm{HSO}_{4}\right)\left(\mathrm{H}_{2} \mathrm{PO}_{4}\right)$, with an electron probability density of $50 \%$, projected along [001]. Central $X$ atom in the $X_{\mathrm{O}_{4}}$ group shown in gray, all other atoms shown in white. The $x$ coordinate (elevation) of $X$ atoms is given. Cs atoms reside at sites with $x$ coordinates approximately \pm 0.5 that of the $X$ atoms. 
Table 3. Anisotropic displacement parameters $\left(\AA^{2}\right)$ for $\mathrm{Cs}_{2}\left(\mathrm{HSO}_{4}\right)\left(\mathrm{H}_{2} \mathrm{PO}_{4}\right)$

The anisotropic displacement parameter takes the form $-2 \pi^{2}\left[h^{2} a^{* 2} U^{11}+\ldots+2 h k a^{*} b^{*} U^{12}\right]$.

\begin{tabular}{|c|c|c|c|c|c|c|}
\hline & $U^{11}$ & $U^{22}$ & $U^{33}$ & $U^{23}$ & $U^{13}$ & $U^{12}$ \\
\hline Cs & $0.032(1)$ & $0.028(1)$ & $0.031(1)$ & $0.000(1)$ & $0.000(1)$ & $-0.004(1)$ \\
\hline S & $0.020(1)$ & $0.019(1)$ & $0.026(1)$ & $-0.001(1)$ & $0.004(1)$ & $-0.003(1)$ \\
\hline $\mathrm{P}$ & $0.020(1)$ & $0.019(1)$ & $0.026(1)$ & $-0.001(1)$ & $0.004(1)$ & $-0.003(1)$ \\
\hline $\mathrm{O}(1)$ & $0.030(2)$ & $0.029(2)$ & $0.039(2)$ & $-0.013(1)$ & $0.008(1)$ & $-0.006(1)$ \\
\hline $\mathrm{O}(2)$ & $0.033(2)$ & $0.031(2)$ & $0.037(2)$ & $0.004(1)$ & $0.010(1)$ & $-0.006(1)$ \\
\hline $\mathrm{O}(3)$ & $0.032(2)$ & $0.031(2)$ & $0.039(2)$ & $-0.006(1)$ & $0.012(1)$ & $-0.003(1)$ \\
\hline $\mathrm{O}(4)$ & $0.032(2)$ & $0.030(2)$ & $0.050(2)$ & $0.007(1)$ & $-0.008(1)$ & $-0.002(1)$ \\
\hline
\end{tabular}

Table 4. Coordination polyhedra in $\mathrm{Cs}_{2}\left(\mathrm{HSO}_{4}\right)\left(\mathrm{H}_{2} \mathrm{PO}_{4}\right)$

(a) Interatomic distances $(\AA)$ in the caesium polyhedron. Sum of the bond valences at Cs also given; see text for details of calculation.

$\begin{array}{ll}\mathrm{Cs}(1)-\mathrm{O}(2)^{\mathrm{i}} & 3.055(4) \\ \mathrm{Cs}(1)-\mathrm{O}(2)^{\mathrm{ii}} & 3.063(4) \\ \mathrm{Cs}(1)-\mathrm{O}(1)^{\mathrm{iii}} & 3.151(3) \\ \mathrm{Cs}(1)-\mathrm{O}(3)^{\mathrm{iv}} & 3.196(4) \\ \mathrm{Cs}(1)-\mathrm{O}(3) & 3.208(3) \\ \sum S=1.10 & \langle 3.27\rangle\end{array}$

(b) Interatomic distances $(\AA)$ and angles $\left(^{\circ}\right)$ in the phosphorus/sulfur tetrahedron. Sum of the bond valences at the S/P site also given.

$\begin{array}{llllllr}\mathrm{S} / \mathrm{P} & \text { Distance } & \text { Angle } & \text { Distance } & \text { Angle } & \text { Distance } & \text { Angle } \\ \mathrm{O}(2) & 1.461(2) & & & & \\ \mathrm{O}(1)_{A / D} \text { vii } & 1.513(2) & 111.1(2) & 2.453(4) & & & \\ \mathrm{O}(4)_{D} & 1.517(2) & 110.2(2) & 2.442(4) & 107.6(2) & 2.445(4) & 108.1(2) \\ \mathrm{O}(3)_{A} & 1.520(2) & 112.6(2) & 2.480(4) & 107.1(2) & 2.439(4) & \mathrm{O} \\ \Sigma S=5.51 & \langle 1.503\rangle & \mathrm{O}(2) & \mathrm{O}(2) & \mathrm{O}(1) & \mathrm{O}(1) & \mathrm{O}(4)\end{array}$

$\dagger$ Symmetry codes: (i) $1-x+\frac{3}{2}, y-\frac{1}{2},-z-\frac{1}{2}$; (ii) $x-\frac{1}{2},-y+\frac{1}{2}, z+\frac{1}{2}$; (iii) $-x+\frac{3}{2}, y+\frac{1}{2},-z+\frac{1}{2}$; (iv) $x+\frac{1}{2},-y+\frac{1}{2}, z+\frac{1}{2}$; (v) $x, y, z+1$; (vi) $-x+2,-y,-z$; (vii) $x, y, z-1$.

In Table 5 the geometric features of the two hydrogen bonds are presented, as are the sum of the bond valences at the two proton sites. The bond valence of the $\mathrm{O}-\mathrm{H}$ bond was calculated according to

$$
S(\mathrm{H}-\mathrm{O})=\exp \left[\left(5.61-d_{\mathrm{H}-\mathrm{O}}\right) / 0.403\right]
$$

where $d_{\mathrm{H}-\mathrm{O}}$ is the hydrogen-to-oxygen distance, again measured in $\AA$ (Alig et al., 1994). For comparison, the results obtained by Averbuch-Pouchot \& Durif (1981) for $\left(\mathrm{NH}_{4}\right)_{2}\left(\mathrm{HSO}_{4}\right)\left(\mathrm{H}_{2} \mathrm{PO}_{4}\right)$ are also presented [proton positions were not reported in the case of $\mathrm{K}_{2}\left(\mathrm{HSO}_{4}\right)\left(\mathrm{H}_{2} \mathrm{PO}_{4}\right)$ (Averbuch-Pouchot \& Durif, 1980)]. The ammonium compound offers the advantage of an absence of heavy X-ray scatterers and permitted those authors to accurately determine proton positions. In both Tables 4 and $5 \mathrm{O}$ atoms that serve as donors and those that serve as acceptors in the hydrogen bonds are given the subscripts $D$ and $A$, respectively. As is the norm, we define the $\mathrm{O}$ atom that is closer to the proton as the donor, and the atom further away as the acceptor, i.e. $\mathrm{O}_{D}-\mathrm{H} \cdots \mathrm{O}_{A}$. $\mathrm{O}$ atoms that are related by a symmetry element serve as mixed donor/acceptors in the hydrogen bond and are denoted $\mathrm{O}_{A / D}$.

\section{Discussion}

\subsection{Coordination polyhedra}

The structure of $\mathrm{Cs}_{2}\left(\mathrm{HSO}_{4}\right)\left(\mathrm{H}_{2} \mathrm{PO}_{4}\right)$ is shown in projection along [010] in Fig. 4. The structure contains loosely defined $\mathrm{CsO}_{10}$ polyhedra and well defined $\mathrm{XO}_{4}$ tetrahedra. The single, crystallographically distinct $\mathrm{Cs}$ atom has an average $\mathrm{Cs}-\mathrm{O}$ distance of $3.27 \AA$, ranging from a low of 3.055 (4) to a high of 3.622 (4) $\AA$, and a bond-valence sum of 1.10. These values are typical for Cs coordinated polyhedra (Shannon, 1976). The bondvalence sum at the $X$ cation site is 5.51, in good agreement with the value of 5.5 expected for a site occupied by $0.5 \mathrm{~S}^{6+}$ and $0.5 \mathrm{P}^{5+}$. The average $X-\mathrm{O}$ bond length of $1.503 \AA$ lies between the values typically encountered in $\mathrm{PO}_{4}$ and $\mathrm{SO}_{4}$ tetrahedra, $\sim 1.52$ and $\sim 1.47 \AA$, respectively (Shannon, 1976), again agreeing with our assignment of mixed $\mathrm{P} / \mathrm{S}$ occupancy on this site. The 
Table 5. Interatomic distances $(\stackrel{\AA}{A})$ and angles $\left(^{\circ}\right)$ between atoms involved in hydrogen bonds in $\mathrm{Cs}_{2}\left(\mathrm{HSO}_{4}\right)\left(\mathrm{H}_{2} \mathrm{PO}_{4}\right)$ Entries given in italics refer to the results for $\left(\mathrm{NH}_{4}\right)_{2}\left(\mathrm{HSO}_{4}\right)\left(\mathrm{H}_{2} \mathrm{PO}_{4}\right)$ (Averbuch-Pouchot \& Durif, 1981).

$\begin{array}{llllllll} & \mathrm{O} \text { Neighbors } & d(\mathrm{O} \cdots \mathrm{O}) & d\left(\mathrm{O}_{D}-\mathrm{H}\right) & d\left(\mathrm{O}_{A}-\mathrm{H}\right) & \sum S(\mathrm{H}) & \angle\left(\mathrm{O}_{D} \mathrm{HO}_{\mathrm{A}}\right) & \angle\left(X \mathrm{O}_{\mathrm{D}} \mathrm{H}\right) \\ \mathrm{H}(1) & \mathrm{O}(1)_{A / D}-\mathrm{O}(1)_{A / D} & 2.542(5) & 0.953 & 1.624 & 1.08 & 160.6 & 109.5 \\ & \mathrm{O}(4)_{D}-\mathrm{O}(3)_{\mathrm{A}} & 2.551(6) & 0.71(6) & 1.85(6) & & 175(9) & 1.09 .5 \\ \mathrm{H}(2) & & 2.550(4) & 0.957 & 1.633 & 1.07 & 158.2 & 178(7) \\ & & & & & & & \end{array}$

tetrahedra are rather regular, as expected for $\mathrm{PO}_{4}$ and $\mathrm{SO}_{4}$ anions, with tetrahedral angles that range from $107.1(2)$ to $112.6(3)^{\circ}$.

\subsection{Hydrogen bonds}

The chemical and geometric features of the hydrogen bonds in $\mathrm{Cs}_{2}\left(\mathrm{HSO}_{4}\right)\left(\mathrm{H}_{2} \mathrm{PO}_{4}\right)$ appear rather typical, Table 5. The $\mathrm{O}-\mathrm{O}$ distances observed about the bonds formed by $\mathrm{H}(1)$ and $\mathrm{H}(2)$ in $\mathrm{Cs}_{2}\left(\mathrm{HSO}_{4}\right)\left(\mathrm{H}_{2} \mathrm{PO}_{4}\right)$, both $\sim 2.54 \AA$, suggest that these bonds are of 'medium' strength and, according to the correlation noted by Ichikawa (1978) between $\mathrm{O}-\mathrm{O}$ and $\mathrm{O}-\mathrm{H}$ distances, $\mathrm{O}_{D}-\mathrm{H}$ bond lengths of the order $1.05 \AA$ are to be expected. In the case of the $\mathrm{O}(1)-\mathrm{O}(1)^{\prime}$ bond an $\mathrm{O}_{D}-$ $\mathrm{H}$ bond of the order $1 \AA$ implies that the proton cannot reside precisely between the two $\mathrm{O}(1)$ atoms, that is, at the inversion center which relates them. Clear displacement of the proton from the center of symmetry was noted in the case of $\left(\mathrm{NH}_{4}\right)_{2}\left(\mathrm{HSO}_{4}\right)\left(\mathrm{H}_{2} \mathrm{PO}_{4}\right)$ (AverbuchPouchot, 1981). Furthermore, in the well characterized compounds $\mathrm{CsH}_{2} \mathrm{PO}_{4}$ (Nelmes \& Choudhary, 1978) and $\mathrm{KH}_{2} \mathrm{PO}_{4}$ (Nelmes et al., 1987), hydrogen bonds between symmetry-related $\mathrm{O}$ atoms with lengths 2.46 (1) and 2.4946 (6) $\AA$, respectively, have been observed. In these bonds also the proton is displaced from the center of symmetry and resides in a double-minimum symmetric potential well, i.e. the bond is 'disordered'. A similar, local disordering of the $\mathrm{H}(1)$ proton is thus highly probable in $\mathrm{Cs}_{2}\left(\mathrm{HSO}_{4}\right)\left(\mathrm{H}_{2} \mathrm{PO}_{4}\right)$, as indicated directly by the structural refinement.

Unlike the first bond, the $\mathrm{H}(2)$ hydrogen bond in $\mathrm{Cs}_{2}\left(\mathrm{HSO}_{4}\right)\left(\mathrm{H}_{2} \mathrm{PO}_{4}\right)$ exhibits some slightly unusual features. As stated above, the absence of a symmetry

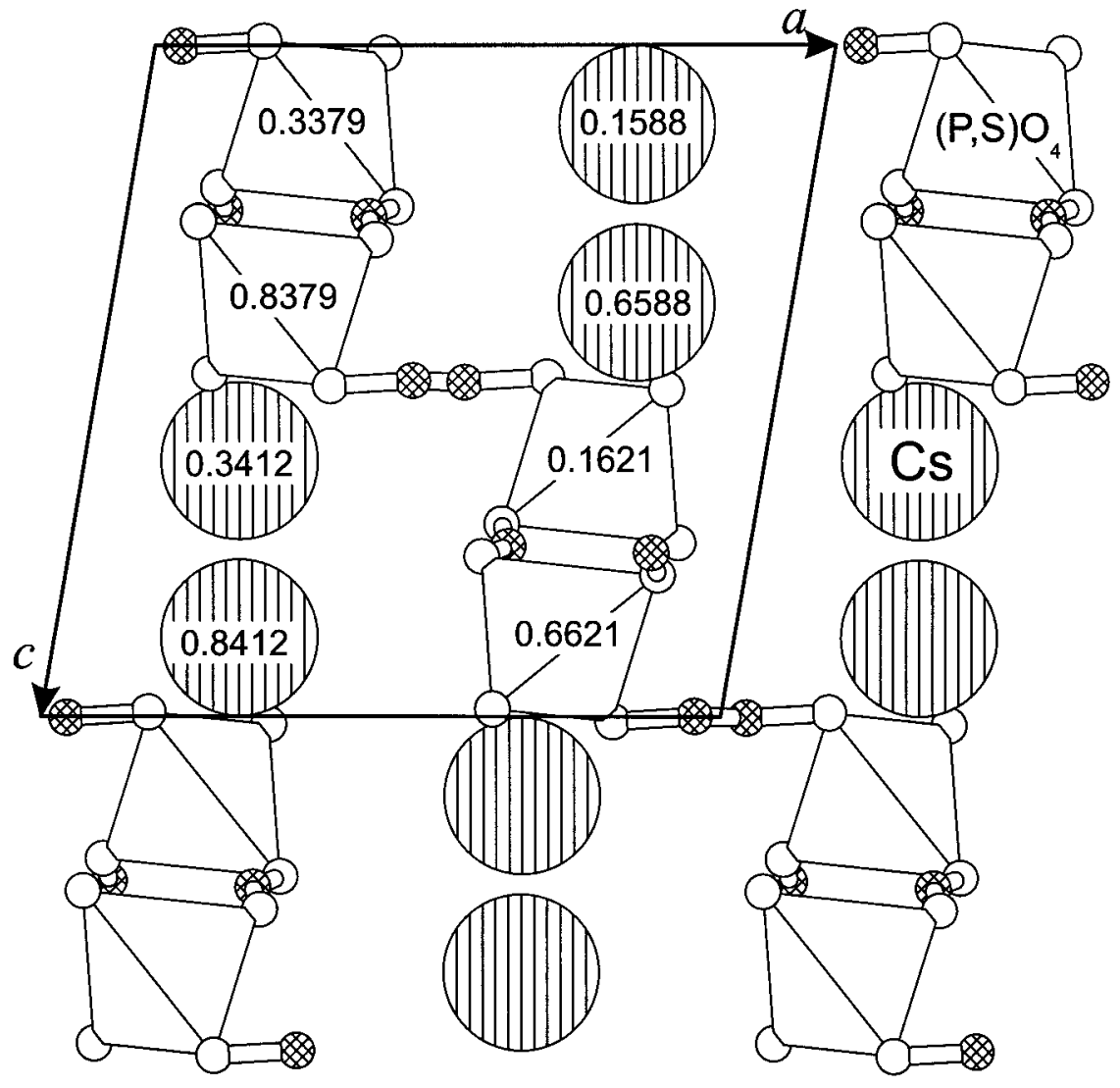

Fig. 4. Projection of the structure of $\mathrm{Cs}_{2}\left(\mathrm{HSO}_{4}\right)\left(\mathrm{H}_{2} \mathrm{PO}_{4}\right)$ along [010]. The $z$ coordinate of the $\mathrm{Cs}$ and $X$ atoms is given. $\mathrm{O}$ atoms are shown as ligands in a tetrahedral group; spheres with cross-hatching represent protons. 
operation relating the $\mathrm{O}$ atoms associated with this bond, $\mathrm{O}(3)$ and $\mathrm{O}(4)$, implies that the potential well about $\mathrm{H}(2)$ should be asymmetric. The similarity of the $X-\mathrm{O}(3)$ and $X-\mathrm{O}(4)$ bond lengths, in contrast, suggests that these two $\mathrm{O}$ atoms have a very similar chemical role in the hydrogen bond, despite their formal crystallographic independence. Moreover, these bonds are comparable in length to the $X-\mathrm{O}(1)_{A / D}$ bond. These observations may be explained by the presence of an unusual, double-minimum asymmetric well between $\mathrm{O}(3)$ and $\mathrm{O}(4)$, containing minima at the positions $\mathrm{H}(2)$ and $\mathrm{H}(2 a)$ that lie at comparable energy levels. In such a case $\mathrm{O}(3)$ and $\mathrm{O}(4)$ serve as mixed acceptor/donor atoms in the $\mathrm{H}(2)$ hydrogen bond, much as $\mathrm{O}(1)$ does for the $\mathrm{H}(1)$ bond. At the very local level, which of these two minina is occupied may well depend on whether the neighboring $X$ species is a $\mathrm{S}$ atom or a $\mathrm{P}$ atom. In $\left(\mathrm{NH}_{4}\right)_{2}\left(\mathrm{HSO}_{4}\right)\left(\mathrm{H}_{2} \mathrm{PO}_{4}\right)$ (Averbuch-Pouchot \& Durif, 1981), in contrast, a single $\mathrm{H}(2)$ site was identified and found to be rather equidistant from the two $\mathrm{O}$ atoms, Table 5. Neutron diffraction and/or NMR experiments will be necessary to sort out these details in the present compound.

\subsection{Tetrahedral linkage}

The structure of $\mathrm{Cs}_{2}\left(\mathrm{HSO}_{4}\right)\left(\mathrm{H}_{2} \mathrm{PO}_{4}\right)$ is comprised of zigzag chains of $\mathrm{Cs}$ cations and of $\mathrm{XO}_{4}$ anions that extend along [010] and alternate with one another in a checkerboard fashion, Fig. 4. The zigzag nature of the chains is expressed in terms of an alternating elevation of $\mathrm{XO}_{4}$ tetrahedra or Cs cations along $c$. Each $\mathrm{XO}_{4}$ tetrahedron is linked to three neighboring $\mathrm{XO}_{4}$ tetrahedra via hydrogen bonds. Two of these bonds, those formed by $\mathrm{H}(2)$ protons, link the tetrahedra along the chain direction, whereas the third, that formed by $\mathrm{H}(1)$, links neighboring chains. Schematically, this bonding configuration is described as shown below

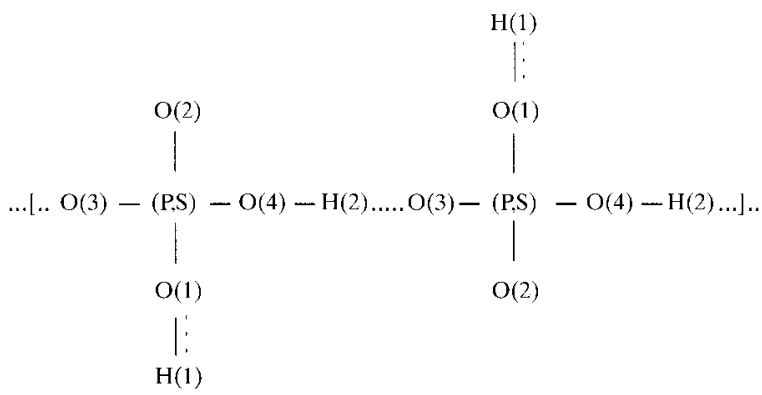

where $\cdots$ denotes a bond between $\mathrm{O}_{A / D}$ and a 'disordered' proton, - denotes a normal $X-\mathrm{O}$ or $\mathrm{O}_{D}-\mathrm{H}$ bond and $\cdots$ denotes a $\mathrm{O}_{A}-\mathrm{H}$ bond.

The manner in which the $X \mathrm{O}_{4}$ chains are linked together gives rise to an overall planar structure. Specifically, the 'upper' tetrahedra, those with higher elevation in $a$, within one zigzag chain are linked to the 'lower' tetrahedra in the neighboring chain displaced along [101], Fig. 4. This distribution of hydrogen bonds generates $\mathrm{H}_{3}\left(X_{\mathrm{O}}\right)$ sheets, shown in Fig. 5, that lie parallel to $(\overline{1} 01)$.

\subsection{Comparison to related structures}

The arrangement of Cs cations and $\mathrm{XO}_{4}$ anions in $\mathrm{Cs}_{2}\left(\mathrm{HSO}_{4}\right)\left(\mathrm{H}_{2} \mathrm{PO}_{4}\right)$ is very similar to that in $\beta-\mathrm{Cs}_{3}\left(\mathrm{HSO}_{4}\right)_{2}\left(\mathrm{H}_{2-x}\left(\mathrm{~S}_{x} \mathrm{P}_{1-x}\right) \mathrm{O}_{4}\right)$ (Haile et al., 1998), $\alpha-\mathrm{Cs}_{3}\left(\mathrm{HSO}_{4}\right)_{2}\left(\mathrm{H}_{2} \mathrm{PO}_{4}\right)$ (Haile, Kreuer \& Maier, 1995) and $\mathrm{CsHSO}_{4}$ (II) (Belushkin et al., 1991). All three of these compounds are also based on zigzag Cs and $\mathrm{XO}_{4}$ chains, which again alternate in a checkerboard fashion. From a purely crystallographic perspective, the present compound differs from these three in that the chains in $\mathrm{Cs}_{2}\left(\mathrm{HSO}_{4}\right)\left(\mathrm{H}_{2} \mathrm{PO}_{4}\right)$ extend in a direction which is parallel to the unique axis in the monoclinic structure, whereas in the other compounds the chains are perpendicular to that axis. Further differences arise from the manner in which the differing proton contents, which is a direct result of the differing $\mathrm{S}: \mathrm{P}$ ratios, are accommodated. In $\mathrm{CsHSO}_{4}$ (II) each $\mathrm{XO}_{4}$ group is, by definition, a sulfate and hydrogen bonds exist only along the chain. The proton to $X \mathrm{O}_{4}$ group ratio is $1: 1$ and, accordingly, two hydrogen bonds are formed per tetrahedral unit (Belushkin et al., 1991). In $\alpha$ $\mathrm{Cs}_{3}\left(\mathrm{HSO}_{4}\right)_{2}\left(\mathrm{H}_{2} \mathrm{PO}_{4}\right)$ every third $X \mathrm{O}_{4}$ group along the chain is a phosphate group. Two additional hydrogen bonds are formed at the $\mathrm{PO}_{4}$ anion group, each chain is linked to two neighboring chains via the bonds at the $\mathrm{PO}_{4}$ group and an overall three-dimensional structure is generated (Haile, Kreuer \& Maier, 1995). The structure of $\beta-\mathrm{Cs}_{3}\left(\mathrm{HSO}_{4}\right)_{2}\left(\mathrm{H}_{2-x}\left(\mathrm{~S}_{x} \mathrm{P}_{1-x}\right) \mathrm{O}_{4}\right)$ is rather similar to that of $\alpha-\mathrm{Cs}_{3}\left(\mathrm{HSO}_{4}\right)_{2}\left(\mathrm{H}_{2} \mathrm{PO}_{4}\right)$, with only slight differences in the nature and occupancy of the hydrogen bonds within the chains (Haile et al., 1998). In the present compound, $\mathrm{Cs}_{2}\left(\mathrm{HSO}_{4}\right)\left(\mathrm{H}_{2} \mathrm{PO}_{4}\right)$, the X-ray data suggest that sulfate and phosphate groups are randomly distributed over the single $X \mathrm{O}_{4}$ anion site in a 1:1 ratio. The proton to $X_{4}$ group ratio is $1.5: 1$ and, accordingly, three hydrogen bonds are formed per tetrahedral unit. The absence of any ordering of $\mathrm{S}$ and $\mathrm{P}$ species would render $\mathrm{Cs}_{2}\left(\mathrm{HSO}_{4}\right)\left(\mathrm{H}_{2} \mathrm{PO}_{4}\right)$ unique amongst the four mixed sulfate phosphate compounds discovered to date in the $\mathrm{CsHSO}_{4}-\mathrm{CsH}_{2} \mathrm{PO}_{4}$ system. It also differs from the other compounds in that there is an odd number of hydrogen bonds per $\mathrm{XO}_{4}$ group. In the other compounds the $X_{\mathrm{O}_{4}}$ groups have either two hydrogen bonds (those along the chain) or four hydrogen bonds (two along the chain plus two to neighboring chains). The presence of three hydrogen bonds per $\mathrm{XO}_{4}$ group in $\mathrm{Cs}_{2}\left(\mathrm{HSO}_{4}\right)\left(\mathrm{H}_{2} \mathrm{PO}_{4}\right)$ may be responsible for the apparent 'tilting' of the zigzag axis of the chain with respect to the chain direction (Fig. 4) and thus the absence of a unique axis perpendicular to the chains.

Within the $\mathrm{CsHSO}_{4}-\mathrm{CsH}_{2} \mathrm{PO}_{4}$ system, two compounds, $\mathrm{CsH}_{2} \mathrm{PO}_{4}$ (Nelmes \& Choudhary, 1978) and 
$\mathrm{Cs}_{5}\left(\mathrm{HSO}_{4}\right)_{3}\left(\mathrm{H}_{2} \mathrm{PO}_{4}\right)_{2}$ (Haile \& Calkins, 1998), like $\mathrm{Cs}_{2}\left(\mathrm{HSO}_{4}\right)\left(\mathrm{H}_{2} \mathrm{PO}_{4}\right)$, have two-dimensional hydrogenbond networks. The structure of the new compound differs, however, quite dramatically from these two. The end-member phosphate contains layers in which every $\mathrm{PO}_{4}$ group is involved in four hydrogen bonds. It can be described in terms of the linkage of straight chains that extend along [100] (when referred to space group $B 2_{1} / m$ ) that are linked to form zigzag layers which are parallel to (001). Alternatively, its structure can be viewed to result from the linkage of zigzag chains that extend along [010], to yield the same zigzag layers (Nelmes \& Choudhary, 1978). The mixed sulfate-phosphate $\mathrm{Cs}_{5}\left(\mathrm{HSO}_{4}\right)_{3}\left(\mathrm{H}_{2} \mathrm{PO}_{4}\right)_{2}$ has a rather complex structure, being comprised of alternating $\mathrm{CsH}_{2} \mathrm{PO}_{4}$-like double layers and $\mathrm{CsHSO}_{4}$-like triple layers (Haile \& Calkins, 1998). Thus, differences in the P:S ratios are accommodated in a variety of different manners in these otherwise chemically quite similar compounds.

\subsection{Phase transformations}

The superprotonic phase transformation in $\mathrm{Cs}_{2}\left(\mathrm{HSO}_{4}\right)\left(\mathrm{H}_{2} \mathrm{PO}_{4}\right)$ differs from those of the other members in the $\mathrm{CsHSO}_{4}-\mathrm{CsH}_{2} \mathrm{PO}_{4}$ system, not only because of its two-step nature, discussed above, but also because it occurs at an unusually low temperature and involves an unusually large heat of transformation. The transition temperatures $T_{c}$ in $\mathrm{CsHSO}_{4}, \quad \beta$ $\mathrm{Cs}_{3}\left(\mathrm{HSO}_{4}\right)_{2}\left(\mathrm{H}_{2-x}\left(\mathrm{~S}_{x} \mathrm{P}_{1-x}\right) \mathrm{O}_{4}\right) \quad$ and $\quad \alpha-$ $\mathrm{Cs}_{3}\left(\mathrm{HSO}_{4}\right)_{2}\left(\mathrm{H}_{2} \mathrm{PO}_{4}\right)$ are 414,398 and $395 \mathrm{~K}$, respectively, whereas the heats of transformation are 23, 30 and $40 \mathrm{~J} \mathrm{~g}^{-1}$ (Baranowski et al., 1989; Haile et al., 1997; Haile, Lentz et al., 1995). These results suggest, at first glance, that the introduction of phosphorus causes a monotonic decrease in $T_{c}$ and a corresponding monotonic increase in $\Delta H_{\text {trans. }}$. However, one may not be justified in drawing such a generalized conclusion from merely four data points. Furthermore, it is unclear how or why phosphorus should have such an effect. Until the high-temperature phases of all of these compounds are solved, and indeed the question of whether or not $\mathrm{CsH}_{2} \mathrm{PO}_{4}$ undergoes a superprotonic transition is resolved (Lee, 1996), one can only speculate on the details of the relationships between structure, chemistry and physical properties in solid acids. Nevertheless, the presence of a superprotonic transition in $\mathrm{Cs}_{2}\left(\mathrm{HSO}_{4}\right)\left(\mathrm{H}_{2} \mathrm{PO}_{4}\right)$ clearly demonstrates that superprotonic behavior is independent of the dimensionality of the hydrogen-bond network, and also of the local nature of the bonds, that is, whether the bonds are ordered or disordered, symmetric or asymmetric. Any

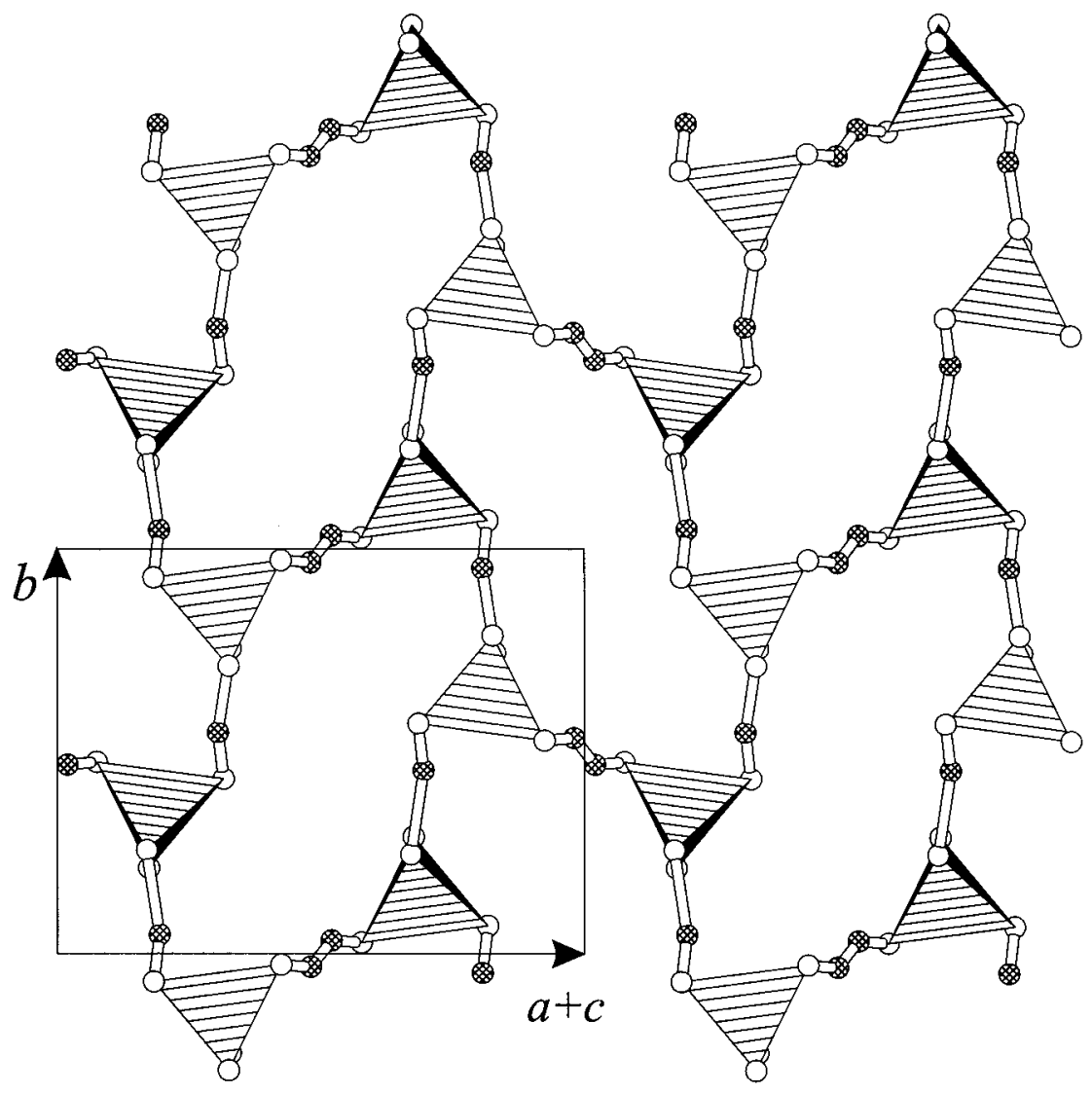

Fig. 5. Projection of the structure of $\mathrm{Cs}_{2}\left(\mathrm{HSO}_{4}\right)\left(\mathrm{H}_{2} \mathrm{PO}_{4}\right)$ in a direction perpendicular to (101), showing the $\mathrm{H}_{3}\left(X \mathrm{O}_{4}\right)$ sheet that lies parallel to this plane. $\mathrm{O}$ atoms shown as ligands in a tetrahedral group; spheres with cross-hatching represent protons. The portion of the structure depicted does not include Cs atoms. 
model that attempts to explain superprotonic transitions must similarly predict superprotonic behavior without reference to these parameters.

\section{Concluding remarks}

The rich variety of structures encountered in the $\mathrm{CsHSO}_{4}-\mathrm{CsH}_{2} \mathrm{PO}_{4}$ system demonstrates that slight changes in stoichiometry can produce dramatic changes in structure and, in particular, in the nature of the hydrogen-bond network. Indeed, one can imagine even for the given stoichiometry of $\mathrm{Cs}_{2}\left(\mathrm{HSO}_{4}\right)\left(\mathrm{H}_{2} \mathrm{PO}_{4}\right)$ a very different structure might be obtained if the $\mathrm{PO}_{4}$ and $\mathrm{SO}_{4}$ groups were, rather than randomly distributed, ordered along the zigzag chains, in analogy to $\alpha$ $\mathrm{Cs}_{3}\left(\mathrm{HSO}_{4}\right)_{2}\left(\mathrm{H}_{2} \mathrm{PO}_{4}\right)$ (Haile, Kreuer \& Maier, 1995). Our studies also reveal that while superprotonic behavior is relatively insensitive to structure and chemistry, the transition temperature is rather sensitive to them. Thus, we are hopeful that with continued investigations, the details of the structure-chemistry-property relations in solid acids will be elucidated and, ultimately, roomtemperature superprotonic phases will be obtained.

The authors are pleased to acknowledge the assistance of Dr Ma Chi with the electron microprobe analysis. This work was funded in part by the National Science Foundation via a National Young Investigator Award to SMH, and in part by the Irvine Foundation.

\section{References}

Alig, H., Lösel, J. \& Trömel, M. (1994). Z. Kristallogr. 209, 1821.

Armstrong, J. T. (1995). Microbeam Anal. 4, 177-200.

Averbuch-Pouchot, M. T. \& Durif, A. (1980). Mat. Res. Bull. 15, 427-430.

Averbuch-Pouchot, M. T. \& Durif, A. (1981). Mat. Res. Bull. 16, 407-411.

Baranov, A. I., Fedosyuk, R. M., Schagina (sic), N. M. \& Shuvalov, L. A. (1984). Ferroelectr. Lett. 2, 25-28.
Baranowski, B., Friesel, M. \& Lundén, A. (1989). Physica A, 156, 353-363.

Belushkin, A. V., David, W. I. F., Ibberson, R. M. \& Shuvalov, L. (1991). Acta Cryst. B47, 161-166.

Brown, I. D. \& Altermatt, D. (1985). Acta Cryst. B41, 244-247.

Calkins, P. M. (1996). M.S. thesis. University of Washington.

Chisholm, C. R. I. \& Haile, S. M. (1999). Solid State Ion. Submitted.

Cromer, D. T. \& Waber, J. T. (1974). International Tables for Crystallography, edited by A. J. A. Wilson, Vol. IV, pp. 128134. Birmingham: Kynoch Press. (Present distributor Kluwer Academic Publishers, Dordrecht.)

Dowty, E. (1999). ATOMS. Shape Software. 521 Hidden Valley Rd, Kingsport, TN 37663, USA.

Haile, S. M. \& Calkins, P. M. (1998). J. Solid State Chem. 140, 251-265.

Haile, S. M., Calkins, P. M. \& Boysen, D. (1998). J. Solid State Chem. 139, 373-387.

Haile, S. M., Calkins, P. M. \& Boysen, D. (1997). Solid State Ion. 97, 145-151.

Haile, S. M., Kreuer, K.-D. \& Maier, J. (1995). Acta Cryst. B51, 680-687.

Haile, S. M., Lentz, G., Kreuer, K.-D. \& Maier, J. (1995). Solid State Ion. 77, 128-134.

Ichikawa, M. (1978). Acta Cryst. B34, 2074-2080.

Ichikawa, M. (1987). Acta Cryst. B43, 23-28.

Lee, K. S. (1996). J. Phys. Chem. Solids, 57, 333-342.

Merinov, B. V., Baranov, A. I., Shuvalov, L. A. \& Shchagina, N. M. (1991). Sov. Phys. Cryst. 36, 321-324.

Nelmes, R. J. \& Choudhary, R. N. P. (1978). Solid State Commun. 26, 823-826.

Nelmes, R. J., Tun, Z. \& Kuhs, W. F. (1987). Ferroelectrics, 71, 125-141.

Pawlaczyk, Cz., Salman, F. E., Pawlowski, A., Czapla, Z. \& Pietraszko, A. (1986). Phase Transit. 8, 9-16.

Pawlowski, A., Pawlaczyk, Cz. \& Hilczer, B. (1990). Solid State Ion. 44, 17-19.

Shannon, R. D. (1976). Acta Cryst. B32, 751-767.

Sheldrick, G. M. (1985). In Crystallographic Computing 3, edited by G. M. Sheldrick, C. Krüger and R. Goddard, pp. 175-189. Oxford University Press.

Sheldrick, G. M. (1993). In Crystallographic Computing 6, edited by H. D. Flack, L. Parkanyi \& K. Simon, pp. 100-110. Oxford University Press. 